\title{
Luminescence properties of Ti-doped gem-grade zirconia powders
}

\author{
G M PHATAK, K GANGADHARAN, H PAL and J P MITTAL \\ Chemistry Division, Bhabha Atomic Research Centre, Trombay, Bombay 400085, India \\ MS received 26 October 1993; revised 30 December 1993

\begin{abstract}
A detailed investigation on luminescence properties of gem-grade zirconia (NFC) as a function of Ti doping is presented. The effect of various parameters such as $\mathrm{Ti}_{\mathrm{i}}$ concentration, environment of heat treatment and temperature was studied in detail and the optimum conditions for producing zirconia with luminescence properties comparable to standard material determined.
\end{abstract}

Keywords. Zirconia; gem-grade; luminescence.

\section{Introduction}

Gemstones are certain minerals which are highly valued because of their beauty, durability and scarcity. In general, any stone which can fetch a high price if attractively mounted in jewellery is considered as gemstone. Diamond (allotropic form of carbon) is the supreme colourless gemstone. The most popular substitutes for diamond in the past were zircon and colourless sapphire. However, in recent years, cubic zirconia (zirconium dioxide, $\mathrm{ZrO}_{2}$ ) has emerged as the sole alternative to diamond due to the closeness in the properties of diamond and cubic zirconia (except specific gravity). The properties of some of the diamond substitutes are given in table 1 .

India has a well-established zirconium industry and has excellent prospects of becoming one of the most important producers and exporters of gem-grade zirconia. Efforts are under way at the Nuclear Fuel Complex (NFC), Hyderabad, to produce gem-grade $\mathrm{ZrO}_{2}$. In view of this, the present work was undertaken to assess the utility of luminescence studies in the fabrication of proper raw material for gem-grade zirconia.

\subsection{Zirconium dioxide $\left(\mathrm{ZrO}_{2}\right.$, zirconia $)$}

Zirconium is a member of group IV of the periodic table. Baddeleyite $\left(\mathrm{ZrO}_{2}\right)$ and zircon (zirconium orthosilicate, $\mathrm{ZrSiO}_{4}$ ) are at present the main sources for industrial zirconium.

Zirconia is produced by ignition of zirconium hydroxide or other zirconium salts, viz. sulphates and nitrates, obtained during the extraction of zirconium from the minerals. Commercial zirconia is always associated with hafnium as major impurity due to closeness in their crystal radii $\left(\mathrm{Zr}^{4+} 0.79 \AA, \mathrm{Hf}^{4+} 0.78 \AA\right)$. Besides $\mathrm{Hf}$, commercial zirconia also contains $\mathrm{Fe}$ and $\mathrm{Ti}$ as major impurities. Zirconia is very stable and refractory and has a high melting point $\left(>2700^{\circ} \mathrm{C}\right)$. Zirconia displays polymorphism and normally exists in monoclinic form at room temperature, and on heating changes to tetragonal $\left(1250^{\circ} \mathrm{C}\right)$, hexagonal $\left(1900^{\circ} \mathrm{C}\right)$ and cubic $\left(\sim 2300^{\circ} \mathrm{C}\right)$, and upon cooling reverts to monoclinic (Elwell 1979). The cubic form of zirconia is stabilized by addition of $\mathrm{CaO}, \mathrm{MgO}$ or $\mathrm{Y}_{2} \mathrm{O}_{3}$ and finds a variety of applications 
Table 1. Properties of some diamond substitutes.

\begin{tabular}{llccccc}
\hline Material & $\begin{array}{c}\text { Chemical } \\
\text { formula }\end{array}$ & $\begin{array}{c}\text { Hardness } \\
\text { (Mohs scale) }\end{array}$ & $\begin{array}{c}\text { Refractive } \\
\text { index }\end{array}$ & Birefringence & Dispersion & Sp. gravity \\
\hline $\begin{array}{l}\text { Diamond } \\
\text { Cubic zirconia }\end{array}$ & $\mathrm{C}$ & 10.0 & 2.42 & 0 & 0.044 & 3.52 \\
$\begin{array}{l}\text { Zircon } \\
\text { Strontium } \\
\text { titanate }\end{array}$ & $\mathrm{ZrSiO}_{4}$ & 8.0 & 2.16 & 0 & 0.060 & 6.00 \\
& $\mathrm{SrTiO}_{3}$ & 5.6 & 1.92 & 0.059 & 0.039 & 4.69 \\
\hline
\end{tabular}

(Elwell 1979)

such as protective coatings and solid-state electrolyte, apart from a substitute for diamond.

\subsection{Optical properties of zirconia}

Optical properties of cubic zirconia are largely governed by stoichiometric oxygen vacancies and presence of dopants such as rare earths, nickel, chromium, titanium, iron, etc. Weakly reduced cubic zirconia exhibits yellow coloration due to loss of oxygen without any change in structure (Aleksandrov et al 1978; Bonola et al 1991). Black crystals of zirconia are produced on vacuum annealing at $2000^{\circ} \mathrm{C}$ and rapid cooling; blackness is due to partial oxygen loss and the formation of colour centres. On heating in air at $1200^{\circ} \mathrm{C}$, zirconia regains its original colour (Aleksandrov et al 1978). Single-crystal yttria-stabilized cubic zirconia in the as-grown state is reported to be a transparent pale yellow or brown material without any strong absorption in the visible region of the spectrum (Wright et al 1973). Doping with $\mathrm{Ce}$ or $\mathrm{Cr}$ gives orange or red crystals respectively.

The vacancies in $\mathrm{ZrO}_{2}$ crystal may also be created by electroreduction at relatively low temperatures and applied voltages (Bonola et al 1991).

Commercial samples of monoclinic zirconia are reported to exhibit blue-white luminescence with a long persistence when excited by ultraviolet light or cathode rays. However, high-purity zirconia does not respond to ultraviolet or cathode-ray excitation (Sarver 1966). The observed luminescence was believed to be due to the presence of an impurity which works as primary activator and was identified as Ti. Studies on luminescence properties of Ti-doped high-purity zirconia have been reported. Presence of Fe impurity appears to be detrimental to Ti emission. Purity and Ti concentration appear to play an important role in governing the luminescence properties of Ti-doped zirconia (Sarver 1966).

\subsection{Luminescence studies on zirconia}

Zirconia powders from three sources, viz. (i) imported (China) (IC), (ii) MEL (UK) (MEL) and (iii) synthesized indigenously at NFC, Hyderabad, were used for luminescence studies. Detailed luminescence studies were conducted with NFC powders. MEL sample was used as a standard for comparison. In table 2, spectrographic analysis of the above mentioned three samples is given. It is evident that the IC 
Table 2. Analysis of $\mathrm{ZrO}_{2}$ samples*.

\begin{tabular}{|c|c|c|c|}
\hline \multirow[b]{2}{*}{ Element } & \multicolumn{3}{|c|}{ Concentration in ppm on $\mathrm{Zr}$ basis } \\
\hline & IC & MEL & NFC \\
\hline $\mathbf{A l}$ & $<10$ & 15 & \\
\hline B & $<0.5$ & $<0.5$ & $<0.5$ \\
\hline $\mathbf{B i}$ & $<25$ & $<25$ & $<25$ \\
\hline $\mathrm{Ca}$ & 500 & $<50$ & $<50$ \\
\hline Co & $<5$ & $<5$ & $<10$ \\
\hline $\mathrm{Cr}$ & $<10$ & $<10$ & $<25$ \\
\hline $\mathrm{Cu}$ & $<25$ & $<25$ & $<25$ \\
\hline $\mathrm{Fe}$ & $<10$ & $<10$ & $<20$ \\
\hline Hf & - & $1.9 \%$ & - \\
\hline $\mathbf{M g}$ & $<25$ & $<25$ & $<25$ \\
\hline $\mathbf{M n}$ & $<5$ & $<5$ & $<5$ \\
\hline Mo & $<25$ & $<25$ & $<25$ \\
\hline $\mathrm{Ni}$ & $<5$ & $<5$ & $<5$ \\
\hline $\mathrm{Pb}$ & $<25$ & $<25$ & $<25$ \\
\hline $\mathrm{Sb}$ & $<25$ & $<25$ & $<25$ \\
\hline $\mathrm{Si}$ & & 10 & \\
\hline Sn & $<10$ & $<10$ & $<10$ \\
\hline $\mathrm{Ti}$ & $\begin{array}{l}>500 \\
(\sim 2000)\end{array}$ & $\begin{array}{l}>500 \\
(1500)\end{array}$ & 150 \\
\hline $\mathbf{U}$ & $<1$ & $<1$ & $\sim 5$ \\
\hline V & $<10$ & $<10$ & $<10$ \\
\hline $\mathbf{w}$ & $<25$ & $<25$ & $<25$ \\
\hline
\end{tabular}

* Analysis supplied by NFC, Hyderabad.

sample contains higher Ti whereas MEL sample contains higher $\mathrm{Hf}$ and $\mathrm{Ti}$ values compared to NFC zirconia. Fe content of NFC sample is high compared to the other two samples.

It is interesting to note that with $307 \mathrm{~nm}$ excitation of these zirconia samples MEL $\mathrm{ZrO}_{2}$ exhibited strong luminescence with a wide emission band extending below $400 \mathrm{~nm}$ to above $650 \mathrm{~nm}$ with a peak emission at $\sim 473 \mathrm{~nm}$; whereas $\mathrm{IC} \mathrm{ZrO}_{2}$ exhibited relatively weak luminescence. The NFC sample showed weakest luminescence which could be slightly improved by annealing in oxygen for a long time. The very weak luminescence exhibited by NFC sample may be attributed to low Ti content, viz. 150 ppm.

\subsection{Improvement of luminescence properties of NFC zirconia}

In view of the above, it was of interest to study (i) the feasibility of improving the optical properties of NFC zirconia by Ti doping, (ii) to determine the optimum $\mathrm{Ti}$ content to yield zirconia with luminescence comparable to that of MEL, and (iii) the role of oxygen/argon annealing of zirconia if any.

In the present work data on Ti doping of $\mathrm{NFC} \mathrm{ZrO}_{2}$ and its effect on luminescence properties of the powders is presented. 


\section{Preparation of Ti-doped $\mathrm{ZrO}_{2}$ samples}

Gem-grade $\mathrm{ZrO}_{2}$ sample received from a particular batch of NFC, was used as such without further purification. $\mathrm{Ti}$ was doped in $\mathrm{ZrO}_{2}$ sample in concentrations from 0.1 to $1 \mathrm{wt} \%$. Required amount of $\mathrm{Ti}$ sulphate solution and $0.5 \mathrm{~g} \mathrm{ZrO}$ were mixed to form a slurry and evaporated to dryness on a sand bath. The dried product was mixed by grinding and heated in a platinum crucible at $1000^{\circ} \mathrm{C}$ for $1 \mathrm{~h}$ in air, quenched, followed by grinding and further heating to $1100^{\circ} \mathrm{C}$ for $30 \mathrm{~min}$. The cooled product (A) was further annealed in oxygen (B) or argon (C) at $1000^{\circ} \mathrm{C}$ for $1 \mathrm{~h}$.

All the above samples gave blue-white emission on $307 \mathrm{~nm}$ excitation. The excitation and emission spectra were recorded using a Hitachi F-4010 spectrofluorimeter fitted with Hamametsu R-928 F photomultiplier tube. All the luminescence measurements were done with front surface geometry. The powdered samples were packed in a special holder, the front face of which is made of a quartz glass plate. The thickness of the materials packed in the holder was about $0.3 \mathrm{~mm}$ for all the measurements.

The optical properties for the samples A, B and C are summarized in table 3. Data on IC and MEL $\mathrm{ZrO}_{2}$ samples are also included for comparison.

$\mathrm{X}$-ray diffraction patterns were recorded for stock and Ti-doped $\mathrm{ZrO}_{2}$ powders with Ni-filtered $\mathrm{Cu}-\mathrm{K} \alpha$ radiation on a Philips pw 1710 diffractometer. The $\mathrm{X}$-ray diffraction patterns agreed well with that of monoclinic $\mathrm{ZrO}_{2}$ pattern reported in the literature (Smith and Newkirk 1965).

\section{Results}

\subsection{Luminescence studies on zirconia}

With $307 \mathrm{~nm}$ excitation IC, MEL and NFC $\mathrm{ZrO}_{2}$ samples received as such and Ti-doped NFC $\mathrm{ZrO}_{2}$ samples exhibit a wide emission band extending from below $400 \mathrm{~nm}$ to above $650 \mathrm{~nm}$ with a peak emission intensity at $473 \mathrm{~nm}$. Figure 1 shows

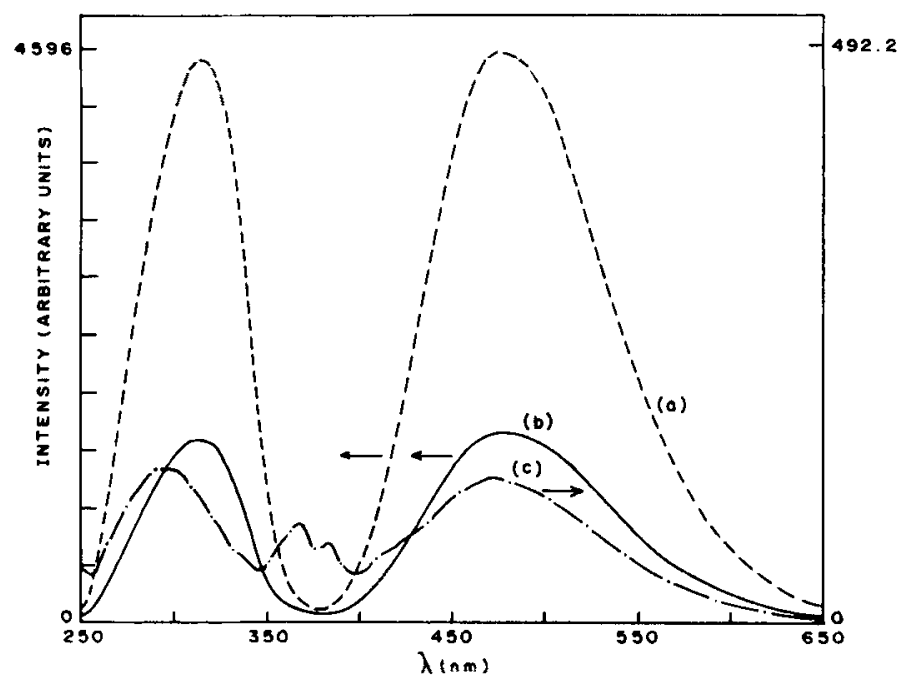

Figure 1. Excitation and emission spectra of $\mathrm{ZrO}_{2}$ : (a) $\mathrm{MEL}$, (b) IC and (c) NFC. 


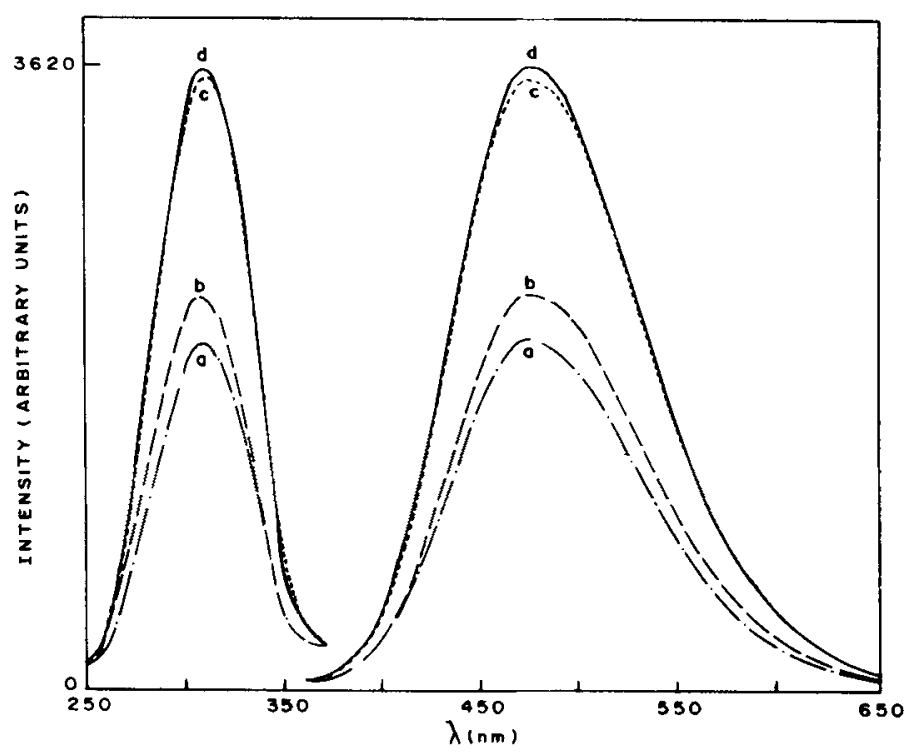

Figure 2. Excitation and emission spectra of Ti-doped NFC $\mathrm{ZrO}_{2}:$ (a) $0 \cdot 2$, (b) $0 \cdot 125$, (c) 0.175 and (d) $0.15 \% \mathrm{Ti}$.

excitation and emission spectra for IC, MEL and NFC $\mathrm{ZrO}_{2}$ samples received as such. Figure 2 shows the excitation and emission spectra for Ti-doped $\mathrm{NFC} \mathrm{ZrO}_{2}$. The emission spectra are similar to that reported in the literature (Sarver 1966) for Ti-doped $\mathrm{ZrO}_{2}$.

\subsection{Effect of Ti doping}

Emission properties of NFC samples were studied as a function of Ti doping. Table 3 shows the intensity of maximum luminescence $\left(I_{\max }\right)$ at $473 \mathrm{~nm}$ when excited at $307 \mathrm{~nm}$ as a function of $\mathrm{Ti}$ content and environment of annealing. From the data in table 3 (column A), it can be seen that $I_{\max }$ increases initially with increase in Ti content, attains a maximum value at $0.15 \mathrm{wt} \% \mathrm{Ti}(1500 \mathrm{ppm})$ in $\mathrm{ZrO}_{2}$ (sample no. 3), and then decreases with increase in Ti doping. The $I_{\max }$ value for $\mathrm{NFC} \mathrm{ZrO}_{2}$ (sample no. 3) is slightly lower compared to $\mathrm{MEL} \mathrm{ZrO}_{2}$ containing $\sim 1500 \mathrm{ppm} \mathrm{Ti}$ (sample no. 13). The lower value for NFC $\mathrm{ZrO}_{2}$ may be attributed to presence of more Fe content, viz. 20 compared to $<10 \mathrm{ppm}$, in MEL sample.

\subsection{Effect of heat treatment environment on emission intensity}

From table 3, it appears that the environment used for $\mathrm{ZrO}_{2}$ powders plays a significant role in determining luminescence properties of Ti-doped $\mathrm{ZrO}_{2}$. Comparison of the data given in table 3 columns $A$ and $B$, and columns $A$ and $C$ brings out remarkable differences in the behaviour of $\mathrm{ZrO}_{2}$ powders containing optimum/near-optimum concentrations of $\mathrm{Ti}$ (sample nos. 2 to 4 ) and samples with non-optimum concentration of $\mathrm{Ti}$ (sample nos. 1 and 5-10) when subjected to oxygen and argon annealing at 
Table 3. Effect of $\mathrm{Ti}$ concentration and environment on emission intensity for gem-grade $\mathrm{ZrO}_{2}$ (NFC) (A: air, B: oxygen, C: argon).

\begin{tabular}{lrrrr}
\hline & \multicolumn{4}{c}{ Emission intensity (relative counts) } \\
\cline { 2 - 5 } Ti (wt\%) & \multicolumn{1}{c}{ A } & B & C & Remarks \\
\hline 0.1 & 495 & 1940 & 489 & NFC \\
0.125 & 2301 & 2206 & 2779 & NFC \\
0.150 & 3620 & 3330 & 2806 & NFC \\
0.175 & 3554 & 3121 & 2749 & NFC \\
0.200 & 670 & 2043 & 1986 & NFC \\
0.300 & 550 & 1669 & 492 & NFC \\
0.400 & 426 & 1585 & 482 & NFC \\
0.500 & 362 & 1557 & 439 & NFC \\
0.600 & 286 & 1001 & 397 & NFC \\
1.000 & 234 & 310 & 273 & NFC \\
0.015 & 125 & 715 & 275 & NFC \\
0.20 & 1503 & 1331 & 1566 & IC \\
0.150 & 4567 & 4443 & 4596 & MEL \\
\hline
\end{tabular}

$1000^{\circ} \mathrm{C}$. With the oxygen annealing of the air-heated (A) sample nos. 2 to 4 , a slight decrease in $I_{\max }$ is observed. However, on argon annealing of these samples the decrease in $I_{\max }^{\max }$ is more pronounced compared to oxygen-annealed samples.

Oxygen annealing of the air-heated (A) sample nos. 1 and 5-10, containing nonoptimum concentrations of $\mathrm{Ti}$, produced a three to four fold increase in $I_{\max }$, whereas Ar annealing has hardly any significant effect on $I_{\max }$.

Behaviour of NFC and MEL samples both containing $\sim 1500$ ppm Ti (sample nos. 3 and 13) on oxygen annealing is comparable.

Comparison of NFC and IC samples both containing $2000 \mathrm{ppm}$ Ti reveals that NFC sample (no. 5) has better luminescence properties than the IC sample no. 12, in spite of higher Fe content.

NFC and MEL $\mathrm{ZrO}_{2}$ containing $\sim 1500 \mathrm{ppm} \mathrm{Ti}$ on further annealing in oxygen at $1300^{\circ} \mathrm{C}$ showed further decrease in $I_{\max }$.

\section{Conclusions}

Luminescence properties of zirconia along with elemental analysis compared with standard give valuable information on role of impurities, Ti doping, environment used in heat treatment and temperature for annealing in the synthesis of gem-grade zirconia and help in the selection of raw material.

\section{Acknowledgement}

The authors wish to thank Dr K Balaramamoorthy and Dr T S Krishnan, NFC, Hyderabad, for supplying the zirconia samples for the present study. 


\section{References}

Aleksandrov U, Osiko U V, Prokhorov A M and Tatarintsev V M 1978 Current topics in material science (ed.) E Kaldis (Amsterdam: North Holland Publishing Company) Vol. 1, Ch. 6, pp 452-458

Bonola C, Camagni P, Omenetto N and Samoggia G $1991 \mathrm{~J}$. Lumin. 48-49 797 and references thervin Elwell D 1979 Man-made gemstones (Chichester. Ellis Harwood Ltd.) Ch. 5, pp. 101-118

Sarver J F 1966 J. Electrochem. Sac. 113124 and references therein

Smith D K and Newkirk H W 1965 Acta Crystallogr. 18983

Wright D A, Thorp J S, Aypar A and Buckley H P 1973 J. Mater. Sci. 24619 